\title{
Health Referral Enterprise Architecture Design in Indonesia
}

\author{
Putu Wuri Handayani ${ }^{1}$, Ave Adriana Pinem ${ }^{1}$, Qorib Munajat ${ }^{1}$, Fatimah Azzahro ${ }^{1}$, \\ Achmad Nizar Hidayanto ${ }^{1}$, Dumilah Ayuningtyas ${ }^{2}$, Arief Sartono ${ }^{3}$ \\ ${ }^{1}$ Faculty of Computer Science, Universitas Indonesia, West Java, Indonesia \\ ${ }^{2}$ Faculty of Public Health, Universitas Indonesia, West Java, Indonesia \\ ${ }^{3}$ Agency for Assessment and Application of Technology, Ministry for Research, Technology and Higher Education of the Republic of Indonesia, Jakarta, Indonesia
}

Objectives: In this study an enterprise architecture (EA) was developed for a health referral information system (HRIS) for individual healthcare in Indonesia with reference to the Open Group Architecture Framework (TOGAF) 9.1. The HRIS includes patient referrals for vertical and horizontal references (internal and external), specimen referrals, and health personnel referrals. Methods: This research was a qualitative study that used the interview and observation method of the Primary Health Care Information System (SIMPUS) application developed by the Agency for Assessment and Application of Technology (BPPT). The interviews were conducted at South Tangerang City Government Health Office with five resource persons who were responsible for conducting health referral processes. Results: The EA of the HRIS includes the principles of architecture, business, application, data, and technology architecture. Twelve principles, four referral processes, and three application reference modules and centralized applications comprise the architecture of the HRIS. The HRIS is a centralized integrated application that uses application program interface (API) to integrate with SIMPUS. Conclusions: The proposed architecture was developed in an integrated and comprehensive manner for the individual healthcare referral process, which can be implemented by regulators and healthcare facilities. This architecture can also help regulators and healthcare facilities to standardize and integrate health referral data and related processes.

Keywords: Primary Health Care, Hospitals, Referral and Consultation, Health Information Systems, Indonesia

Submitted: December 11, 2018

Revised: January 13, 2019

Accepted: January 23, 2019

\section{Corresponding Author}

Putu Wuri Handayani

Faculty of Computer Science, Universitas Indonesia, Kampus UI Depok, West Java 16424, Indonesia. Tel: +62-81380883402, E-mail: putu.wuri@cs.ui.ac.id (https://orcid.org/0000-0001-5341-3800)

This is an Open Access article distributed under the terms of the Creative Commons Attribution Non-Commercial License (http://creativecommons.org/licenses/bync/4.0/) which permits unrestricted non-commercial use, distribution, and reproduction in any medium, provided the original work is properly cited.

(C) 2019 The Korean Society of Medical Informatics

\section{Introduction}

In Indonesia, the National Health Insurance (NHI) program enables patients to begin receiving treatment at healthcare facilities, with the result that most healthcare facilities in Indonesia are now receiving an increasing number of patients. The NHI is a tiered referral system for vertical and horizontal referrals. Vertical-tiered reference is initiated by first level healthcare facilities (FKTP) and then proceeds to the advanced healthcare facility of advanced referral (FKRTL), whereas for horizontal referrals, the case is the reverse; the referral process starts from FKRTL and goes to the FKTP. A horizontal reference occurs when a patient is referred to another healthcare facility at the same level. In addition to pa- 
tient referrals, the Ministry of Health (MoH) also sets standards for specimen referrals to healthcare facilities that have limited health equipment for checking specimens; in such cases, the specimens can be referred to healthcare facilities at the next higher level or at the same level. In addition, if a healthcare facility lacks medical experts, a referral of experts may be performed whereby the healthcare facility may apply for licenses to the health service and healthcare facilities that have available experts and as required by the healthcare facility in need. Further, the main basis for the development of the health referral information system (HRIS) refers to Regulation of the Health Minister Number 001 of 2012 and the National Reference Guideline of the Ministry of Health Republic of Indonesia.

As one example of highly complex organizations, healthcare facilities in Indonesia make use of a variety of application software programs to handle the number of patients who seek treatment and facilitate the referral process. However, because current applications have not been able to meet the needs of the process required for referrals, a single healthcare facility may use many applications in the referral process. This condition lengthens the time required for referral-related health services provided by healthcare facilities. The number of existing referral applications is increasing because the health regulator does not apply strategic planning to information system (IS)/information technology (IT) or standard data reference, and there is no comprehensive IS/IT policy in application development in healthcare facilities. Consequently, the regulator and healthcare facilities are forced to develop their respective applications in accordance with the needs of each healthcare facility.

In developing integrated referral applications, comprehensive application development planning can be facilitated by the development of enterprise architecture (EA) applications (IS/IT strategic planning) and data dictionary applications (data governance) [1]. EA can help healthcare facilities to overcome the complexity of the processes of healthcare facilities [1-5]. According to Kettinger et al. [6], the main purpose of EA is to help organizations share a common understanding within organizations and create a shared vision to align business areas with support areas and IT. A commonly used reference framework for describing EA is the Open Group Architecture Framework (TOGAF). Haghighathoseini et al. [7] described how an EA developed with TOGAF can be used for hospitals. In [1], an exploratory and empirical study applied EA principles to hospitals in Portugal. Rijo et al. [1] investigated the role of EA in healthcare organizations and suggested a better framework for creating an integrated EA health information model.

EA is one approach that can be used for planning, designing, and managing information systems. EA is a representation of high-level views of enterprise business processes and IT systems, their relevance, and the extent to which these processes and systems are shared by various parts of the company [8]. EA describes a long-term plan for developing a system or set of systems. The main concept of EA is to describe the target architecture based on the shared vision of the organization for IT development in the future. In addition, the roadmap to be followed from the current architecture to the proposed architecture can be more easily understood in the presence of EA. According to Rijo et al. [1], EA attempts to address two major problems: (1) organizational complexity and (2) the value of investments in information and communication technology. EA can also assist organizations in creating alignment between business and IT activities, creating a unified and standardized IT environment across organizational units, reusing existing IT assets, and sharing common methods for project management and software development across the organization.

EA implementation requires a method or framework that can be used in the development of the EA so that it can manage complex systems and align business and IT for investment. TOGAF is one of the EA frameworks that is most frequently used by organizations because it provides a comprehensive approach to planning, designing, implementing, and managing information architecture in an organization. The TOGAF was developed in 1995 and has advantages due to its flexibility, open-source structure, and systematic nature, focusing on implementation and process cycles. Before defining the architecture in TOGAF, we should define problems and the architecture's scope, and identify stakeholders and architecture principles [9]. A company's architecture in TOGAF includes the following four categories [9]:

(1) Business Architecture: Describes how the business process can achieve organizational goals. Business architecture can be modeled using a flowchart, unified modeling language (UML), or other modeling methods.

(2) Application Architecture: Describes how an application is designed and how it interacts with other applications.

(3) Data Architecture: Describes how a company handles the storage, management, and access of data.

(4) Technology Architecture: A description of the hardware, software, and network infrastructure that supports the application and how those infrastructures interact.

Due to the large number of healthcare facilities that do not have good IS/IT planning for the development of health 


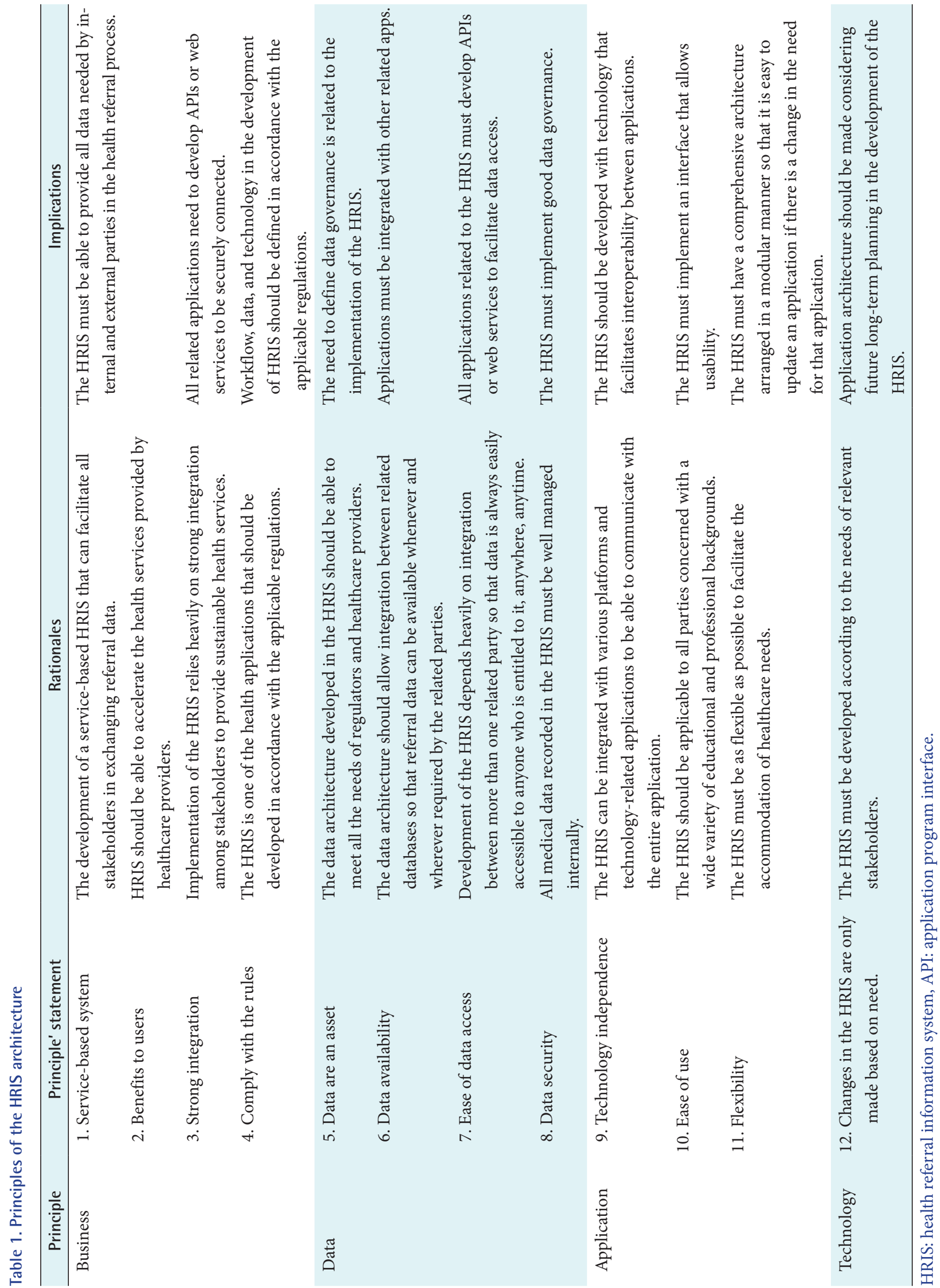


referral systems and still focus on current health referral systems in the individual healthcare (IHC), this study covered the development of EA on tiered referrals within the IHC. This architecture was developed with reference to the TOGAF 9.1. The results of this study will be useful for regulators and healthcare facilities in conducting comprehensive planning in the development of an integrated referral system. It is hoped that comprehensive planning can then facilitate the standardization of health data between regulators and healthcare facilities.

The remainder of this paper is organized as follows. Sections II and III discuss the research methods and the associated EA outcomes that have been developed. Then, discussions and conclusions are provided in Section IV.

\section{Methods}

This research was a qualitative study that used the interview and observation method of the Primary Health Care Information System (SIMPUS) application developed by the Agency for Assessment and Application of Technology (BPPT). The interviews were conducted at the South Tangerang City Government Health Office. Regarding the ethics of this study, we obtained approval from the BPPT by letter (No. B.065/BJIK/KP 05.08/08/2018). In addition, the South Tangerang City Government Agency was chosen because the Health Office is planning to develop a referral system that is integrated with SIMPUS, which is used by most primary healthcare providers (Puskesmas) in the Tangerang Selatan area.

Five employees with the Tangsel City Health Office as a main resource were interviewed, namely, the head of the Health Resources Section, the head of Health Services, the section head of Primary Services, the Reference section head, and an IT staff member of the Health Resources Section. Those individuals were selected because they are responsible for developing the HRIS in the Tangsel City. The interviews were conducted in a structured manner through a list of questions for 30 minutes to one hour at the Tangsel City Health Office. The list of questions was prepared prior to the interviews and are related to (1) problems in implementing a health referral system to define the future architecture principles; (2) health referral system regulations and business processes for developing a business architecture; (3) application features and its architecture that have been implemented and future recommendations that should be implemented in the health referral system to develop the application and technology architecture. The results of the in- terviews were recorded, summarized, codified, synthesized, and analyzed to develop a health referral system architecture. The development of the EA for the HRIS with reference to the TOGAF 9.1 consisted of four stages: problem formulation, literature study, EA development and determination of implications, and conclusions and suggestions. In this process, the following were defined: (1) the architectural principles, problems, and solutions in HRIS development, (2) the business architecture, (3) the application architecture, and (4) the technology architecture.

\section{Results}

\section{Architecture Principles, Problems, and Solutions in Developing the HRIS}

An application's principle of architecture consists of a list of principles to be referred to in the development of referrals. These principles are derived from the needs of the referral process run by healthcare facilities and health regulators. Table 1 explains the principle of the HRIS architecture. The principles defined in the HRIS architecture consist of business principles, data, applications, and technologies. The 12 principles that have been defined must be implemented in the development of HRIS applications. In addition to the architectural principles, the HRIS application is accessed by seven main actors, namely the Directorate of Health Referral of the $\mathrm{MoH}$, the Center of Data and Information (Pusdatin) of the MoH, the Social Security Agency for Health (BPJS-K), provincial and district Health Offices, primary healthcare providers, hospitals, and the community.

\section{Business Architecture}

Based on the National Reference Guideline of the Ministry of Health of the Republic of Indonesia, the processes of referral systems were categorized in three flowcharts, namely patient referral, specimen referral, and medical personnel referral. These process flows were gathered from interview results regarding the business processes implemented in healthcare facilities. The patient referral process is depicted in Figure 1. This workflow starts when a patient registers to receive health services, and medical personnel determine the diagnosis of the patient. If the patient needs to be referred, a referral form must be completed with the name of the referred healthcare facility and other information needed. A referral can be made as an emergency referral or an outpatient referral. Then the patient will be served in the designated healthcare facility, by either emergency or outpatient measures. If a referral is returned, then the referred healthcare facilities 


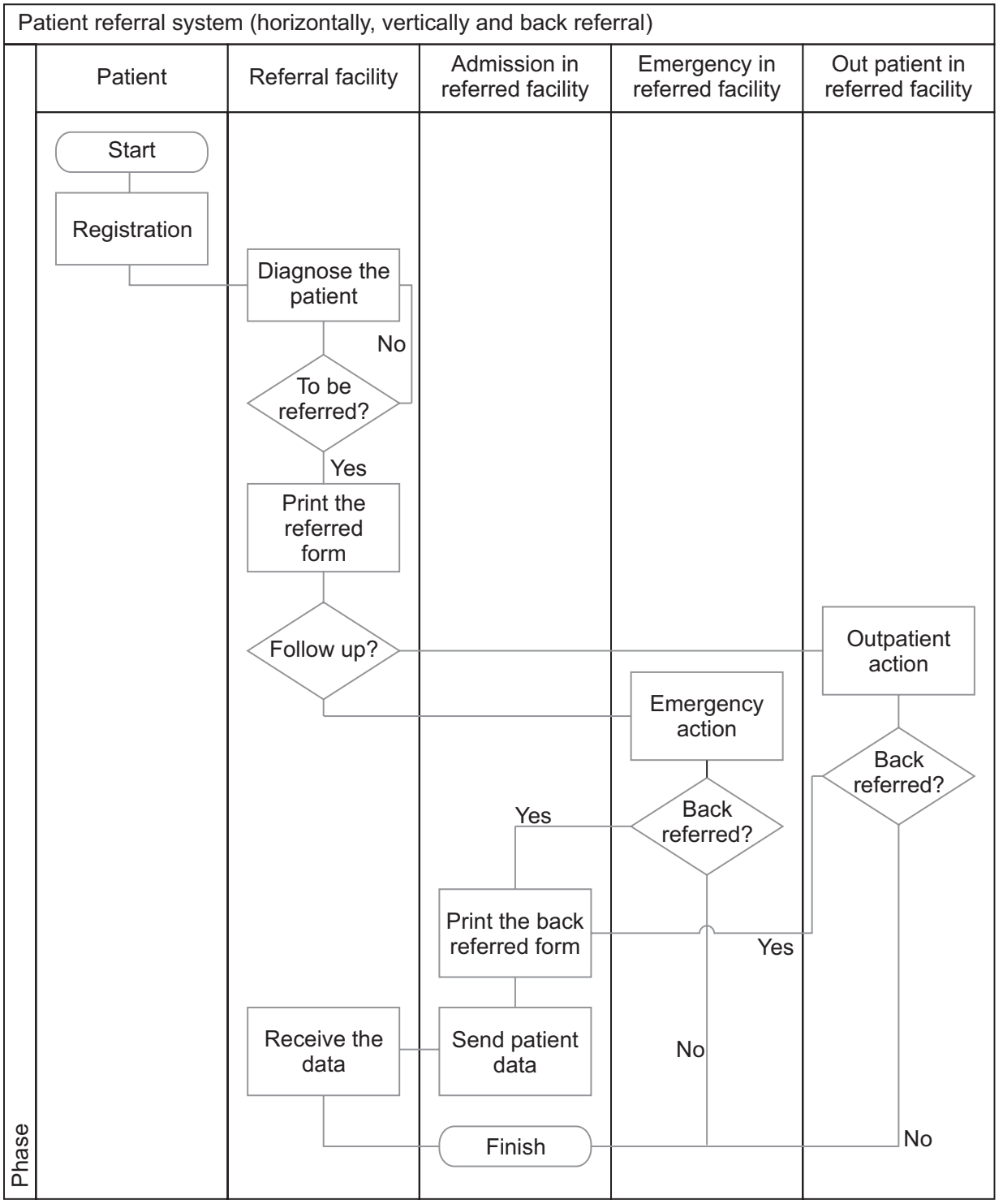

Figure 1. Patient referral flowchart. must fill in a referral form. After that, the referral facility receives the referral data.

The specimen referral process is carried out to facilitate the inspection of specimens that cannot be carried out at the referral facility. This process is started by selecting the type of examination and choosing the referred healthcare facilities. After the required information and supporting documents have been filled out, the specimen will be sent to the referred facility. The examination will be conducted, and the results will be sent to the originating healthcare facility. This process ends with the referring facility receiving the results of the examination.

The medical personnel referral process aims to facilitate a healthcare facility that requires additional medical personnel temporarily. An epidemic or an outbreak is one reason for this special case. This process begins by completion of a form regarding the number of medical personnel needed, the time, and field of expertise. Then, the regulator will accept the request and forward it to the appropriate healthcare facilities. The referred facilities then confirm their approval or rejection of the request. If the request for referral of medical personnel is approved, the referring healthcare facility will receive the information and wait for the medical personnel to be referred.

For the three major processes of the referral system, a use case diagram is modelled as seen in Figure 2. The use case diagram provides an overview of the actors who are users of the system, the role of each actor, and the activities that can be carried out by each actor in the system. This system has 12 use cases that will cover all the activities conducted in the referral system. 

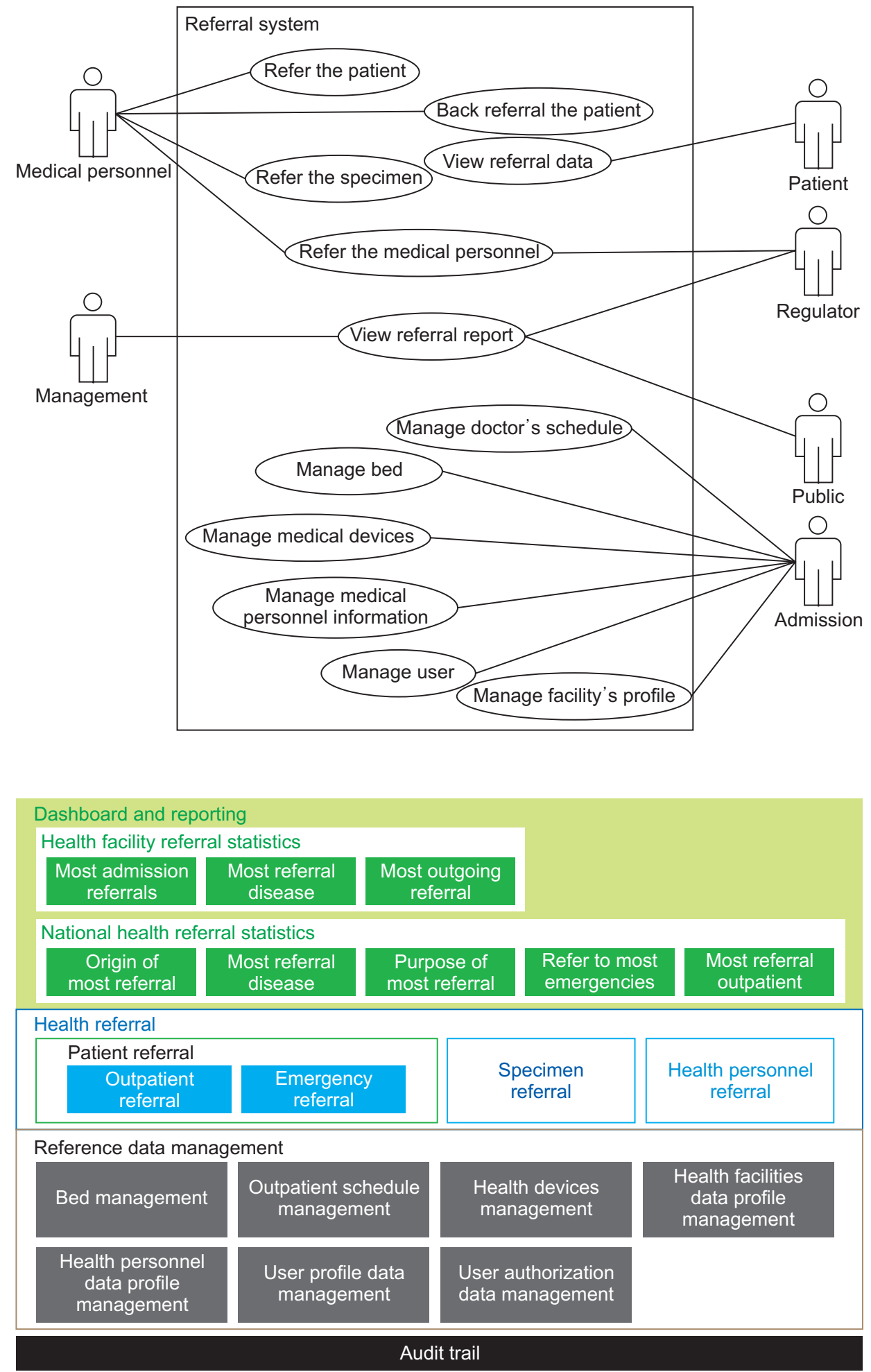

Figure 2. Use case diagram for the referral system.
Figure 3. Health referral information system architecture.

\section{Application Architecture}

The HRIS includes the following modules, namely, reference data management, health referral (policlinic/outpatient, emergency, specimen, and health personnel), and reference data management modules as well as a dashboard and reporting module. Next, HRIS applications can be accessed by regulators, healthcare facilities, and the community. Regulators and healthcare facilities can use the health referral module to manage outpatient, emergency, specimen, and health personnel referral data, while the public can only see referral statistics regarding healthcare facilities and national referral statistics. In summary, the HRIS consists of three modules, 
20 sub-modules, and 56 features. Figure 3 presents the HRIS architecture.

\section{Data Architecture}

The health referral system in Indonesia is supported by a data architecture derived from business and information system architectures. The data architecture describes the list of data entities and the relationships between them. The proposed health referral system consists of 60 data structures or entities to support the main business process. Data structures are grouped based on reference tables, master tables, and transaction tables. Groups of data that are static in nature and rarely change and are referenced by the master table and transactions will be grouped in the reference table. The master table stores data that are changed less frequently than other data, and the master data is referred to by the transaction data. Transaction data is data that often changes.

\section{Technology Architecture}

To implement the architecture principles of the HRIS, the technology architecture for the HRIS is a high-level architecture to describe technology needs and interactions between systems. The HRIS is a centralized integrated application, so all users of the HRIS access the application on a centralized server. The HRIS was developed using open-source technology, namely, PHP and MySQL.

Then, to maintain the performance of the application, a load balancer is needed to distribute the workload between HRIS's servers. There are three main server types for HRIS implementation, namely, the application server, database server, and application program interface (API) server. The API server functions as a bridge for data communication be- tween the HRIS and other systems, such as BPJS-K, the Hospital Information System (SIMRS), SIMPUS, and an application of the Ministry of Home Affairs that is used to manage the personal identification data (e-KTP). The API server also accesses the database server from the HRIS. Separation of servers based on this functionality is intended to improve the scalability of the HRIS. Each server can be added according to the need for increased capacity. The HRIS is accessed via the internet by applying a secure sockets layer (SSL) and firewall for data security between systems. Two types of firewalls are used, namely, an application firewall and a network firewall. Both are implemented to ensure the security of the systems because the HRIS handles confidential information about patients. Authentication is also applied with rolebased access control to limit the data access according to the user privilege. Within the network layer, an intrusion prevention system (IPS), an intrusion detection system (IDS), and network monitoring systems (NMSs) are required to lower the risk of security breach coming from network. The confidentiality of patient data is the main consideration in the design of this security architecture. Figure 4 presents the technology architecture of HRIS.

\section{Discussion}

This study has contributed to the development of the EA for a health referral system in an unprecedented way. This architecture is the latest discovery in Indonesia because, to date, regulators and healthcare facilities have never carried out comprehensive planning in developing their information systems. This may be attributed to the limited competence

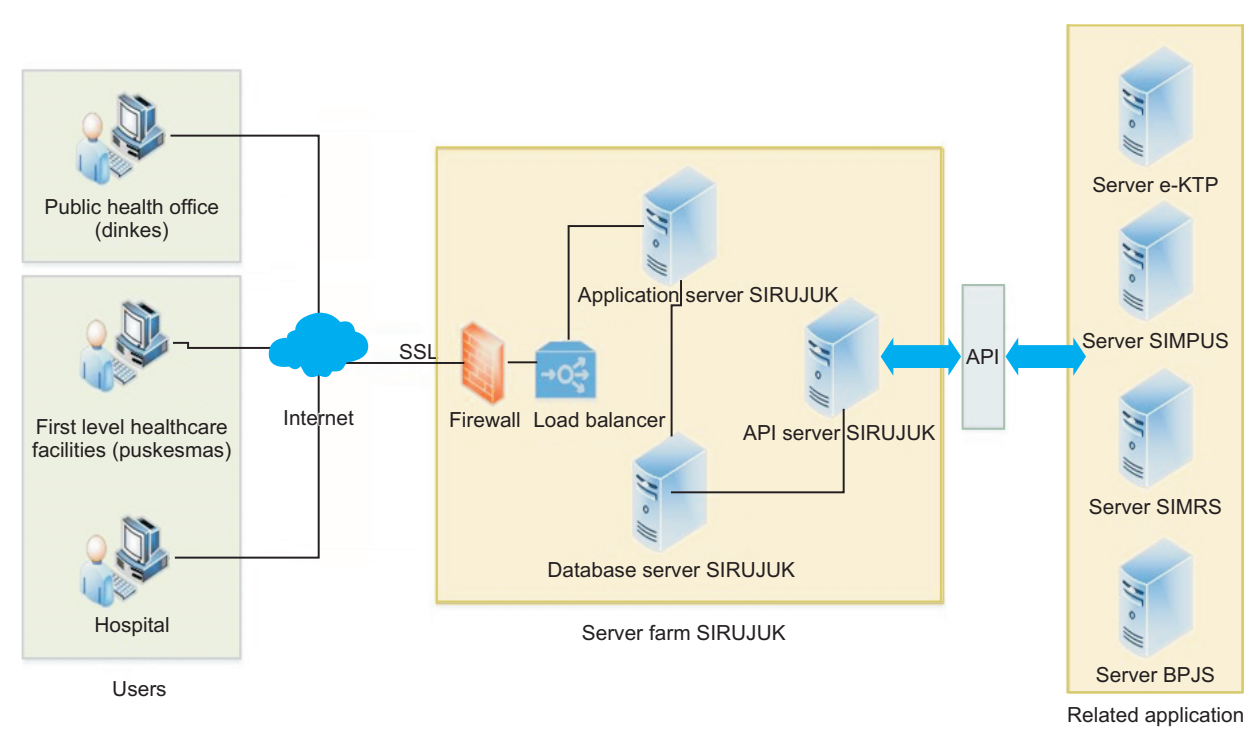

Figure 4. Technology architecture of health referral information system. 
of human resources that have expertise in information technology and the inadequate amount of dedicated human resources for information systems.

In contrast with the existing health referral systems developed by the $\mathrm{MoH}$ and BPJS- $\mathrm{K}$ where their applications could only perform vertical and/or horizontal patient referral, the development of an EA based on the TOGAF can facilitate regulators and healthcare facilities in conducting comprehensive and integrated planning for all relevant stakeholders and can describe who are the stakeholders involved in the referral system. The other difference between this architecture and other health referral architectures is that this architecture provides an API that could be integrated with other related health applications.

The EA developed in this research covers the principles of architecture, business architecture, applications architecture, data architecture, and technology architecture. Twelve principles relating to business principles, data, applications, and technologies have been identified in the development of the EA of this referral system. The business architecture includes the flows of the vertical, horizontal, or back referral processes. The application architecture of the HRIS includes three modules, namely, dashboard \& reporting, referrals, and reference data management. A referral system is a centralized application that enables all interested parties to access the system anytime, anywhere. Besides having complete application features to perform a national health referral process, this application would also be easier to use in term of interoperability with other related applications by regulators and healthcare facilities because the application was created with open-source technology.

This EA can be used by regulators to standardize the processes and data of all healthcare facilities in the referral process. With this EA, health regulators can also carry out planned, comprehensive, and integrated IS/IT development with all interested parties. In addition, healthcare facilities can develop referral applications and other related health applications with reference to the EA guidelines from regulators.

In conclusion, this study demonstrated that the development of EA with TOGAF 9.1 can be used in the implementation of a health referral system for the IHC in Indonesia. An EA can help regulators and healthcare facilities in providing guidance on the development of IS/IT that can align the entire health referral process with IT initiatives to provide valuable benefits in providing optimal health services for regulators and healthcare facilities. This EA for the health referral system covers business principles, data architecture, application architecture, and technology architecture. The health referral processes included in this EA include vertical, horizontal, and back referral processes. The results of this study can be used as the basis for reference in the development of referral applications. In addition, the results of this study can be used as a reference by healthcare facilities in implementing health applications, especially health referral applications, in the future. Finally, future works will develop mobile personal health records that could be integrated with the HRIS so that patients can have their medical records integrated and would be able to conveniently access them.

\section{Conflict of Interest}

No potential conflict of interest relevant to this article was reported.

\section{Acknowledgments}

We want to convey our gratitude to the Directorate General of Higher Education for the Program Dasar Penelitian Unggulan Perguruan Tinggi (PDUPT) Year 2019, as well as the University of Indonesia for their continuous support, particularly from the Directorate of Research and Community Engagement.

\section{ORCID}

Putu Wuri Handayani (http://orcid.org/0000-0001-5341-3800) Ave Adriana Pinem (http://orcid.org/0000-0003-4492-2819) Qorib Munajat (http://orcid.org/0000-0002-7197-6882)

Fatimah Azzahro (http://orcid.org/0000-0001-6551-8116) Achmad Nizar Hidayanto (http://orcid.org/0000-0002-5793-9460) Dumilah Ayuningtyas (http://orcid.org/0000-0002-7621-326X) Arief Sartono (http://orcid.org/0000-0003-0121-031X)

\section{References}

1. Rijo R, Martinho R, Ermida D. Developing an enterprise architecture proof of concept in a Portuguese hospital. Procedia Comput Sci 2015;64:1217-25.

2. Ahsan K, Shah H, Kingston P. The role of enterprise architecture in healthcare-IT. Proceedings of the 6th International Conference on Information Technology: New Generations; 2009 Apr 27-29; Las Vegas, NV. p. 1462-7.

3. Olsen DH. Enterprise architecture management challenges in the Norwegian health sector. Procedia Comput 
Sci 2017;121:637-45.

4. Gebre-Mariam M, Fruijtier E. Countering the "dam effect": the case for architecture and governance in developing country health information systems. Inf Technol Dev 2017;24(2):333-58..

5. Sajid M, Ahsan K. Role of enterprise architecture in healthcare organizations and knowledge-based medical diagnosis system. J Inf Syst Technol Manag 2016;13(2):181-92.

6. Kettinger WJ, Marchand DA, Davis JM. Designing enterprise IT architectures to optimize flexibility and standardization in global business. MIS Q Exec
2010;9(2):95-113.

7. Haghighathoseini A, Bobarshad H, Saghafi F, Rezaei MS, Bagherzadeh N. Hospital enterprise architecture framework (Study of Iranian University Hospital Organization). Int J Med Inform 2018;114:88-100.

8. Tamm T, Seddon P, Shanks G, Reynolds P. How does enterprise architecture add value to organizations? Commun Assoc Inf Syst 2011;28:10.

9. The Open Group Architecture Framework (TOGAF) 9.1 [Internet]. [place unknown]: The Open Group; c2013 [cited at 2019 Jan 15]. Available from: http://pubs.opengroup.org/architecture/togaf9-doc/arch/index.html. 